\title{
INTERVENÇÕES DE ENFERMAGEM ÀS CRIANÇAS COM ANEMIA FALCIFORME NO AMBIENTE HOSPITALAR
}

\author{
Anderson Vinícius Bastos MOTA ${ }^{1}$ \\ Lílian Cristine Moreira NEVES ${ }^{2}$ \\ Sara Cleane Anjos BENTO ${ }^{3}$ \\ Ana Augusta Maciel de SOUZA ${ }^{4}$ \\ Patrick Leonardo Nogueira da SILVA \\ Helder Leone Alves de CARVALHO ${ }^{6}$
}

\begin{abstract}
${ }^{1}$ Enfermeiro pelas Faculdades Integradas Pitágoras de Montes Claros/FIPMoc. Montes Claros (MG), Brasil. E-mail: nogueira_patrick@yahoo.com.br

${ }^{2}$ Enfermeira pelas Faculdades Integradas Pitágoras de Montes Claros/FIPMoc. Montes Claros (MG), Brasil. E-mail: liliancmn@hotmail.com

${ }^{3}$ Enfermeira pelas Faculdades Integradas Pitágoras de Montes Claros/FIPMoc. Montes Claros (MG), Brasil. E-mail: saracleanebento@yahoo.com.br

${ }^{4}$ Enfermeira, mestre em Ciências, Docente do departamento de Enfermagem das Faculdades Integradas Pitágoras de Montes Claros/FIPMoc, Faculdades Santo Agostinho/FASA e Universidade Estadual de Montes Claros/UNIMONTES. Montes Claros (MG), Brasil. E-mail: anamaciel@uol.com.br

${ }^{5}$ Enfermeiro, especialista em Saúde da Família e Didática e Metodologia do Ensino Superior, Pós-Graduando em Enfermagem do Trabalho pela Faculdade de Guanambi/FG. Guanambi (BA), Brasil. E-mail: patrick_mocesp70@hotmail.com

${ }^{6}$ Médico, especialista em Pediatria, Docente do departamento de Medicina da Universidade Estadual de Montes Claros/UNIMONTES. Montes Claros (MG), Brasil. E-mail: helderleone@ hotmail.com
\end{abstract}

Recebido em: 10/06/2015 - Aprovado em: 04/11/2015 - Disponibilizado em: 01/12//2015

\begin{abstract}
RESUMO:
Objetivo: identificar as intervenções de enfermagem prestadas a crianças com anemia falciforme no ambiente hospitalar. Método: trata-se de um estudo descritivo, exploratório com abordagem qualitativa realizada com oito enfermeiros atuantes na pediatria e/ou pronto atendimento de um hospital de Minas Gerais, Brasil. Este estudo foi realizado durante o período de maio a junho de 2011. Utilizou-se um formulário de entrevista semiestruturado para a coleta de dados. Os dados foram analisados por meio da Análise de Conteúdo. O projeto de pesquisa foi aprovado pelo Comitê de Ética em Pesquisa, protocolo n ${ }^{\circ}$ 2447/2011. Resultados: emergiram quatro categorias de análise, sendo elas: reconhecendo a criança com anemia falciforme; revelando os fatores desencadeantes das crises dolorosas; acolhendo e cuidando das crianças com anemia falciforme; Orientando a família e a criança. Conclusão: cabe ao enfermeiro, portanto, além de intervir durante as crises dolorosas, educar a criança e sua família no sentido de prevenir as crises, perceber seus sinais a fim de evitar a sua ocorrência.

Descritores: Anemia falciforme; Criança; Dor; Enfermagem.

\section{NURSING INTERVENTIONS FOR CHILDREN WITH SICKLE CELL DISEASE IN HOSPITAL ENVIRONMENT}

\begin{abstract}
Objective: to identify the nursing interventions provided to children with sickle cell anemia in hospital environment. Method: this is a descriptive and exploratory qualitative study conducted with eight nurses working in pediatrics and/or emergency room of a hospital in Minas Gerais, Brazil. This study was conducted during the period May-June 2011. We used a semi-structured interview form for collecting data. Data were analyzed using content analysis. The research project was approved by the Research Ethics Committee, Protocol No. 2447/2011. Results: four analysis categories emerged, namely: recognizing the child with sickle cell anemia; revealing the triggering factors of painful crises; welcoming and caring for children with sickle cell anemia; Guiding the family and the child. Conclusion: it is up to the nurse, so in addition to intervene during the painful crises, educate the children and their families in order to prevent crises, realize their signs in order to prevent its occurrence.
\end{abstract}

Descriptors: Anemia Sickle Cell; Child; Pain; Nursing. 


\section{INTRODUÇÃO}

A anemia falciforme (AF) é a doença genética de maior prevalência no Brasil, sendo considerada como um problema de saúde pública (CANÇADO; JESUS, 2013). Segundo estimativas da Organização Mundial de Saúde (OMS), a cada ano nascem no Brasil cerca de 3.500 crianças portadoras de doença falciforme, devido complicações diretamente relacionadas à $\mathrm{AF}, 20 \%$ delas não atingirão cinco anos de idade. O diagnóstico precoce e o tratamento adequado representam papel fundamental na redução da morbidade e mortalidade destas crianças (BRASIL, 2006; ROCHA, 2004).

A qualidade de vida é determinada conforme a herança genética e também de fatores sociais, alimentação, prevenção de infecções e assistência de saúde. Determinados pacientes apresentam evolução tranquila, ou até assintomática da doença, outros são internados, por conta das complicações (BATISTA, 2008).

Frequentemente, o portador de doença falciforme cursando com dor são atendidos nos serviços de emergência, por uma equipe médica e de enfermagem que não estão familiarizados com o tratamento adequado da dor e não priorizam a queixa do paciente, relevando a dimensão real do quadro álgico. Esse comportamento, por muitas vezes, aumenta a angústia do paciente e reduz a expectativa em relação ao tratamento, tornando o controle da dor cada vez mais difícil (NAOUM; NAOUM, 2004).

Torna-se necessário conhecer os processos fisiopatológicos da doença e fatores desencadeantes das crises, assim como as intervenções a serem realizadas pela equipe a fim de evitar a ocorrência das crises.

Portanto, este estudo objetivou identificar as intervenções de enfermagem prestadas a crianças com $\mathrm{AF}$, tanto na emergência quanto na admissão hospitalar.

\section{MÉTODO}

Trata-se de um estudo descritivo, exploratório, com abordagem qualitativa realizada nos setores de pronto atendimento e pediatria do Hospital Universitário Clemente de Faria/HUCF localizado na cidade de Montes Claros/MG. A amostra do estudo foi composta por oito enfermeiros que trabalham na pediatria e/ou atuam no pronto atendimento. Os critérios de inclusão estabelecidos para participar da pesquisa foram: ser enfermeiro; trabalhar no pronto atendimento/pediatria; aceitar participar da pesquisa através da assinatura do Termo de Consentimento Livre e Esclarecido (TCLE).

A amostra foi intencional e determinada por saturação, ou seja, as informações foram coletadas até que houvesse repetições em seu conteúdo e informações novas não fossem significativas. A coleta dos dados foi realizada no período de maio a junho de 2011 por meio de uma entrevista 
semiestruturada. Após a coleta dos dados, a análise do conteúdo foi feita de forma sistemática, buscando obter respostas às indagações do estudo, observando o que é repetitivo, bem como procedendo à interpretação contextualizada, confrontando os dados obtidos com referencial teórico.

A análise do conteúdo permitiu a construção das seguintes categorias temáticas: "Reconhecendo a criança com anemia falciforme"; "Revelando os fatores desencadeantes das crises dolorosas"; "Acolhendo e cuidando das crianças com anemia falciforme"; "Orientando a família e as crianças". As categorias foram apresentadas, discutidas e ilustradas com falas extraídas dos discursos dos/as enfermeiros/as participantes.

Obedecendo aos critérios definidos na Resolução no 196/96 do Conselho Nacional de Saúde (CNS), sobre pesquisa envolvendo seres humanos, o projeto deste estudo foi aprovado pelo Comitê de Ética em Pesquisa da Universidade Estadual de Montes Claros (CEP UNIMONTES) sob o parecer consubstanciado no 2447/2011.

\section{RESULTADOS E DISCUSSÃO}

\section{Reconhecendo a criança com anemia falciforme}

Verificou-se que, os profissionais entrevistados detêm conhecimento acerca dos processos fisiopatológicos da doença, embora alguns tenham demonstrado conhecimento limitado sobre o assunto, uma vez que, quando indagados a respeito das principais características da $\mathrm{AF}$, os mesmos referiam, somente, às manifestações clínicas mais comuns apresentadas pelas crianças portadoras de $\mathrm{AF}$ atendidas no serviço, não explicando os motivos pelos quais estas surgem.

Anemia falciforme é uma doença genética, hereditária, né? Caracterizada por uma anormalidade da hemoglobina, a hemácia fica em forma de foice, $e$ causa é oclusão dos vasos na circulação e causando uma hipóxia desses locais, né? (E2)

A hemácia passa por um período de hipóxia e tem uma deformação inicial que dificulta ela captar o oxigênio. Então ela perde a forma normal dela e fica uma forma que dificulta mais ela circular nos vasos, né? (E6)

As crianças que chegam aqui, é, na internação e tratamento vem com sintomas de anemia, né? Uma baixa na hemoglobina é crises álgicas e já ocorreu um caso de retirada do baço devido sequestro esplênico né? (E1)

A AF é uma hemoglobinopatia, onde uma cadeia anormal de hemoglobina (Hb S) é produzida. É uma anemia hereditária caracterizada pela presença de eritrócitos em 
forma de foice e pela hemólise acelerada devida à substituição de um único aminoácido da cadeia beta da hemoglobina. Os indivíduos homozigotos afetados apresentam anemia grave (BRANDEN, 2000). O portador de AF mantém-se sempre anêmico com valores de Hemoglobina entre 7,5 e 10,6 g/100ml (IVO; CARVALHO, 2003).

Com relação às manifestações clínicas frequentemente apresentadas pelas crianças portadoras de AF, sob a ótica dos profissionais entrevistados destacam-se: anemia, entupimento dos vasos, padrão respiratório alterado, desnutrição, desidratação e a dor.

Chegam pra gente pacientes na fase aguda, queixando de dores fortes, né? Chegam fracos, também, padrão respiratório prejudicado (E4).

Dor, palidez, desnutrição, desidratação são os que mais chegam aqui pra gente. (E7)

Tem crises álgicas, né? Por causa do formato da hemácia, entupimentos dos vasos. (E5)

$\mathrm{O}$ portador de AF apresenta dor geralmente devido a episódios de vasooclusão, que ocorrem devido à obstrução dos vasos sanguíneos pelas células falciformes, ocluindo os capilares, causando infartos e disfunção dos órgãos acometidos (BRANDEN, 2000). As crises álgicas ocorrem inesperadamente, representam o quadro mais dramático da doença, muitas vezes impactando diretamente a qualidade de vida do paciente (LOBO; MARRA; SILVA, 2007).

Com relação à crise do sequestro esplênico, os principais sinais clínicos constituem-se no aumento súbito do baço e na redução intensa da hemoglobina, podendo evoluir para choque hipovolêmico. Cabe ressaltar que o sequestro esplênico agudo é a segunda causa mais comum de morte em crianças com AF menores de cinco anos de idade. Esta crise pode ocorrer nos primeiros meses de idade, sendo menos frequente após os seis anos. A etiologia ainda é desconhecida, contudo, infecções virais parecem preceder à maioria dos episódios (BRASIL, 2009).

A crise do sequestro esplênico é um quadro agudo extremamente grave, a criança deve ser levada imediatamente para a emergência. Trata-se da retenção de grande volume de sangue dentro do baço, de forma repentina e abrupta. Verifica-se palidez intensa com anemia aguda, prostração e aumento do abdômen. É importante que a enfermagem ensine os pais de crianças menores de cinco anos a medir o tamanho do baço de seus filhos com doença falciforme e, em caso de suspeita de sequestro esplênico, levar para hospital com maior nível de complexidade (KIKUCHI, 2007). 


\section{Revelando os fatores desencadeantes das} crises dolorosas

A crise dolorosa pode expressar-se após episódio infeccioso, exposição ao frio, a stress físico ou emocional. Ademais, febre, desidratação, acidose, altitude, sono e apneia, alterações climáticas e fatores psicológicos, podem desencadear episódios de vaso-oclusão e consequentemente a dor. $\mathrm{Na}$ maioria dos casos, entretanto, não é possível a identificação dos fatores etiológicos (BRASIL, 2009).

Observa-se que as falas dos enfermeiros condizem com a afirmação acima, uma vez que foram mencionados vários desses fatores, como o estresse, os exercícios físicos intensos, as infecções, a desnutrição, a desidratação e as variações climáticas (frio). Dentre os fatores mais citados por esses profissionais encontram-se à exposição a temperaturas frias $\mathrm{e}$ a desidratação.

Fatores climáticos, né? Pode desencadear também uma época de frio. Aspecto psicológico, algumas situações de estresse podem também ta desencadeando alguma crise dolorosa, né? Exercícios físicos intensos. Desidratação é também. (E2)

Os principais fatores é a questão da desidratação, né? (E4)

Quadro de desidratação, período de frio, infecções, são fatores que normalmente desencadeiam a crise de falcização da hemácia, né? (E6)

Geralmente a incidência das crises álgicas elas aumentam com a baixa de temperatura, durante o frio a gente vê mais internações. (E1)

A desidratação e a hemoconcentração precipitam as crises vaso-oclusivas. Devido à incapacidade de concentrar a urina e consequentemente perda excessiva de água, os indivíduos com doença falciforme são particularmente suscetíveis à desidratação. Sendo Assim, a manutenção de boa hidratação é importante, especialmente durante episódios febris, calor excessivo, ou situações que apresentem diminuição do apetite (BRASIL, 2009).

É importante o conhecimento da doença e dos fatores desencadeantes das crises, os mesmos devem ser compreendidos pelo enfermeiro e sua equipe de forma que produza efeitos positivos e garanta uma assistência de qualidade ao paciente (SILVA; MARQUES, 2007).

\section{Acolhendo e cuidando das crianças com anemia falciforme}

As intervenções de enfermagem frequentemente citadas pelos enfermeiros do pronto atendimento foram à hidratação e a analgesia. Entretanto, duas profissionais se destacaram ao salientar a preocupação com o 
acolhimento e conforto da criança com AF. O mesmo não foi observado nos demais relatos.

Aqui no pronto socorro vamos fazer o primeiro atendimento, administração de, conforme prescrição médica, de medicamentos analgésicos, né? Procurar um ambiente confortável, na medida do possível, cuidar do conforto dele. (E4)

A gente acolhe o paciente $e$ procura um local mais confortável para o paciente ficar, tenta, na maioria das vezes, ser o mais rápido possível, né? $O$ médico prescreve a analgesia, né? Hidratando o paciente $e$ orientando a mãe sobre esse cuidado. Procura tratar as crises álgicas que ele tem no hospital, o tratamento mais rápido. (E5)

A atitude acolhedora do profissional é a chave para identificação dos motivos de busca por atenção e, consequentemente, para intervenções mais resolutivas. O objetivo é que profissional consiga escutar o usuário, perceber as diversas dimensões relacionadas ao motivo da procura por atendimento $\mathrm{e}$ identificar risco e vulnerabilidade, de maneira a orientar, priorizar e decidir sobre os encaminhamentos necessários para a resolução do problema do paciente (BRASIL, 2009).

$$
\text { O papel do enfermeiro na doença }
$$
falciforme consiste em ajudar aliviar a dor do doente, administrando as intervenções necessárias para aliviá-la, sejam intervenções farmacológicas ou não farmacológicas, bem como, avaliando a eficácia dessas intervenções, monitorando os efeitos adversos e servindo como interlocutor quando as prescrições não são eficazes no alívio da dor. Cabe ressaltar, também, que o enfermeiro serve como educador para o paciente e a família, a fim de torná-los capazes de manejar as intervenções prescritas quando apropriadas (SILVA; MARQUES, 2007).

Quando comparadas às intervenções de enfermagem realizadas na pediatria e no pronto atendimento, percebe-se que, os cuidados dispensados, na maioria das vezes, às crianças em crises álgicas, no pronto atendimento, se limitam à hidratação e analgesia, enquanto que na pediatria utilizamse outros recursos além desses já descritos, como a aplicação de calor, estimulação da deambulação, na medida do possível, bem como a inserção de atividades recreativas durante a internação hospitalar.

As intervenções são auxilio no tratamento da algia, é uma aplicação de calor, elevação dos membros, administração de medicamento, né? De analgésicos e a manutenção da soroterapia. (E1)

Geralmente nossas crianças internam com as crises dolorosas, 
então a princípio um cuidado de enfermagem é tá identificando os locais que estão manifestando estas dores, é administrando os analgésicos, né? De acordo com as prescrições médicas, tentando aliviar as dores, também, com compressas mornas nos locais de manifestação da dor e a gente também tenta, na medida, que a criança possa tá movimentado, é, que ela participe das atividades da pedagogia hospitalar. (E2)

Cabe ressaltar que, o quadro restrito de funcionários é uma das dificuldades encontradas pelos profissionais do pronto atendimento para garantir uma assistência integral a essas crianças, segundo uns dos entrevistados.

Como o pronto socorro a gente tem um quadro de funcionários restritos, né? Não tem como você dá uma assistência integral a pessoa, né? Ficar um profissional por conta, né? Pra às vezes fazer uma massagem periférica, né? (E8)

A Resolução COFEN n ${ }^{\circ}$ 168/1993 determina que cabe ao Enfermeiro Responsável Técnico da instituição garantir os recursos humanos necessários à assistência de enfermagem e à segurança do paciente (COREN, 1997). Contudo, a execução e decisão sobre o recrutamento desse pessoal são realizadas, muitas vezes, por profissionais de outras categorias, que consideram somente a questão custo, ignorando a real necessidade quanti-qualitativa de recursos humanos para o desenvolvimento dessa assistência (CAMPEDELI et al., 1987). É por esse motivo que a lotação de pessoal de enfermagem é hoje uma preocupação constante dos enfermeiros administradores e dos pesquisadores dessa área (ANTUNES; COSTA, 2003).

Outra questão abordada foi a possível simulação de uma crise álgica por parte do paciente falcêmico para receber determinado medicamento, ou, a subestimação da dor do outro pela equipe de enfermagem.

O paciente, às vezes, simula uma crise ou a pessoa da enfermagem pensa que ta simulando $e$, às vezes, tem uma resistência a dar esse analgésico. (E6)

A dor não pode ser subestimada, devese lembrar de que cada pessoa tem um limiar de dor, alguns podem ficar agitados, chorando alto e mesmo gritando. Deve-se considerar também que, além da dor, haverá ainda o estresse causado pelo ambiente hospitalar e a lembrança da dor mais forte (KIKUCHI, 2007).

\section{Orientando à família e a criança}

Apesar dos profissionais do pronto atendimento relatarem que não fornecem orientações à criança e/ou a seus familiares durante a permanência destes no setor, nem 
mediante a liberação do paciente para casa, percebeu-se que, a maior parte dos profissionais reconhece a importância das orientações de enfermagem à criança e a sua família, tanto em nível ambulatorial quanto após admissão hospitalar.

Dificilmente damos orientações aqui, eles entram para a clínica $e$ lá recebem as orientações pra casa. (E4)

Aqui no pronto socorro a gente não da nenhuma orientação. A criança consulta e se precisar internar ela interna; se não precisar ela não fica aqui no pronto socorro. Quando ela é internada na pediatria, de lá ela recebe a alta $e$ recebe as orientações, quando ela não é internada ela não recebe nenhuma orientação e ela vai embora. (E5)

É mais voltado pra esses fatores desencadeantes, né? Ter mais cuidado com períodos de inverno, com infecções, né? Deixar a criança sempre bem aquecida é fazer uma ingesta hídrica adequada, né? (E6)

Deve-se orientar a família que, em razão de mecanismos compensatórios internos, as pessoas com doença falciforme devem ser adaptadas a conviver com níveis mais baixos de hemoglobina; elaborar uma alimentação equilibrada; orientar a respeito do sequestro esplênico; sobre a importância de ingerir líquido, e por fim, orientar quanto aos cuidados de enfermagem com manuseio, diluição, conservação de medicamentos para evitar contaminação (KIKUCHI, 2007).

É importante orientar paciente e mães da necessidade de procurar atendimento médico sempre que houver febre persistente; dor torácica e dispneia; dor abdominal, náuseas e vômito; cefaleia; letargia ou alterações de comportamento; aumento do baço. Além disso, para auxiliar na obtenção do bem estar social e mental, o profissional deve educá-los acerca da doença e instruílosacerca do acompanhamento ambulatorial, sendo assim, visitas a múltiplos centros devem ser desencorajadas (BRASIL, 2009).

\section{CONSIDERAÇÕES FINAIS}

Compreender a doença, bem como dos fatores desencadeantes das crises dolorosas são de extrema relevância para subsidiar as ações de enfermagem, garantindo assim, a sobrevida da criança. $\mathrm{O}$ conhecimento limitado dos enfermeiros entrevistados acerca da AF, bem como o déficit nas orientações de enfermagem à criança com essa doença e sua família, deixa explicito a necessidade de se capacitar e formar profissionais capazes tanto de atuar durante as crises dolorosas quanto de educar a família e/ou a criança de modo a evitar a ocorrência dessas crises, orientandoos como evitá-las e perceber seus sinais. 
O enfermeiro possui um papel fundamental no tratamento à criança com AF, pois está em contato direto com o paciente e sua família, logo, poderá conhecer e compreender melhor suas necessidades e anseios, essenciais para garantir uma assistência de enfermagem de qualidade a esses pacientes e suas peculiaridades.

\section{REFERÊNCIAS}

ANTUNES, A. V.; COSTA, M. N. Dimensionamento de pessoal de enfermagem em um hospital universitário. Revista LatinoAmericana de Enfermagem. São Paulo, v. 11, n. 6, p. 832-839, 2003.

BAtista, T. F. Con(Vivendo) com a anemia falciforme: o olhar da enfermagem para o cotidiano de adolescentes [Dissertação]. Salvador (BA): Escola de Enfermagem, Universidade Federal da Bahia, 2008.

BRANDEN, P. S. Enfermagem maternoinfantil: enfermagem prática. $2^{\mathrm{a}} \mathrm{ed}$. Rio de Janeiro: Reichman e Affonso; 2000.

BRASIL. Ministério da Saúde. Manual de Anemia Falciforme para Agentes Comunitários de Saúde. Brasília; 2006.

BRASIL. Ministério da Saúde. Agencia Nacional de Vigilância Sanitária. Manual de eventos agudos em doença falciforme. Brasília: ANVISA; 2009.

CAMPEDELI, M. C. et al. Cálculo de pessoal de enfermagem: competência da enfermeira. Revista da Escola de Enfermagem da USP. São Paulo, v. 21, n. 1, p. 3-15, 1987.

CANÇADO, R. D.; JESUS, J. A. A doença falciforme no Brasil. Revista Brasileira de Hematologia e Hemoterapia. São Paulo, v. 29, n. 3, p. 204-206, 2013.

COREN. CONSELHO REGIONAL DE ENFERMAGEM DE MINAS GERAIS. Resolução COFEN no 168/1993 de 06 de outubro de 1993. Legislação e Normas. Belo Horizonte (MG); 1997.

IVO, M. L.; CARVALHO, E. C. Assistência de enfermagem a portadores de anemia falciforme, à luz do referencial de Roy. Revista Latino-Americana de Enfermagem. Ribeirão Preto (SP), v. 11, n. 2, p. 192-198, 2003.

KIKUCHI, B. A. Assistência de enfermagem na doença falciforme nos serviços de atenção básica. Revista Brasileira de Hematologia e Hemoterapia. São Paulo, v. 29, n. 3, p. 331$338,2007$.

LOBO, C.; MARRA, V. N.; SILVA, R. M. G. Crises dolorosas na doença falciforme. Revista Brasileira de Hematologia e 
Hemoterapia. São Paulo, 29, n. 3, p. 247258, 2007.

NAOUM, P. C.; NAOUM, F. A. Doenças das células falciformes. São Paulo: Sarvier; 2004.

ROCHA, H. H. G. Anemia falciforme. Rio de Janeiro: Rubio; 2004.

SILVA, D. G.; MARQUES， I. R. Intervenções de enfermagem durante crises álgicas em portadores de anemia falciforme. Revista Brasileira de Enfermagem. Brasília, v. 60, n. 3, p. 327-330, 2007. 